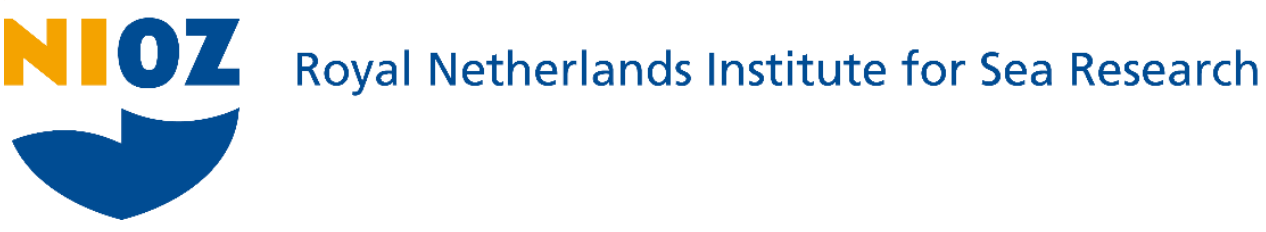

This is a pre-copyedited, author-produced version of an article accepted for publication, following peer review.

Van Haren, H. (2020). High-Resolution temperature observations of a shallow lagoon in the South Pacific (Bora Bora). Journal of Coastal Research, 36, 536

Published version: https://dx.doi.org/10.2112/jcoastres-d-19-00154.1

NIOZ Repository: http://imis.nioz.nl/imis.php?module=ref\&refid=328071

[Article begins on next page]

The NIOZ Repository gives free access to the digital collection of the work of the Royal Netherlands Institute for Sea Research. This archive is managed according to the principles of the Open Access Movement, and the Open Archive Initiative. Each publication should be cited to its original source - please use the reference as presented.

When using parts of, or whole publications in your own work, permission from the author(s) or copyright holder(s) is always needed. 


\title{
High-Resolution Temperature Observations of a Shallow Lagoon in the South Pacific (Bora Bora)
}

\section{Hans van Haren}

Royal Netherlands Institute for Sea Research (NIOZ) and Utrecht University 1790 AB Den Burg, The Netherlands

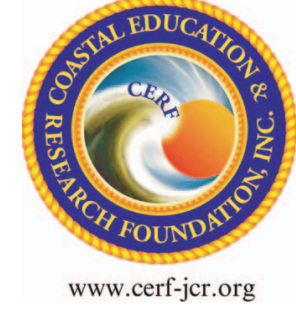

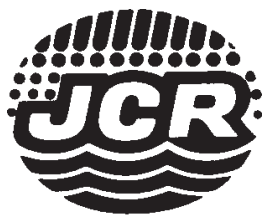

www.JCRonline.org

\begin{abstract}
van Haren, H., 2020. High-resolution temperature observations of a shallow lagoon in the South Pacific (Bora Bora) Journal of Coastal Research, 36(3), 536-544. Coconut Creek (Florida), ISSN 0749-0208.

The daily cycle of heating and cooling of the near-surface ocean may be quite different in the open ocean compared with a shallow lagoon with a seafloor that is a few meters deep and can be heated directly by the sun. This solar radiation can affect the local benthic communities. To study the physical processes associated with the daily cycle of the South Pacific lagoon surrounding Bora Bora, a vertical string of five high-resolution temperature sensors is moored at a 2-m-deep site for 3 weeks. Besides standard ocean warming (mostly during the day) and cooling (mostly at night), the sensors show relatively highest temperature near the lagoon floor during the warming phase and weakly stable stratification toward the end of the cooling phase. During the warming phase, highly variable stratification is observed extending into the water column, but only under conditions of calm weather and turbid waters. Under trade winds and clear waters, the lowest sensor or sensors show consistently higher temperature variability than higher sensors with spectral slopes indicative of shear and/or convective turbulence. During the cooling phase, the lower sensor shows consistently very low variance (nonturbulent), while other sensors show a spectral slope around the buoyancy frequency, evidencing weakly stratified waters supporting internal waves. These observations contrast with open-ocean near-surface observations of stable stratification during the warming phase and turbulent free convection during the cooling phase. Thus, lagoons seem to resemble the atmosphere more than the ocean in daytime thermodynamics and possibly act as a natural solar pond with bottom conductive heating (when salinity compensates for unstable temperature variations).
\end{abstract}

ADDITIONAL INDEX WORDS: Shallow tropical lagoon, daytime heating from below, internal waves.

\section{INTRODUCTION}

The daily open-ocean near-surface heating response pattern relates to one crucial difference between the atmosphere and the ocean: the atmosphere is cooled at a higher geopotential level than where it is heated, while the ocean is heated and cooled at its top (Sandström, 1908). Because warm air or water is generally less dense than cold air or water, daytime heating generates turbulent, vertical, natural and free convective motions in the atmospheric boundary layer, resulting in an effective heat engine (Peixoto and Oort, 1992). In contrast, daytime solar radiation heats the ocean from above, with most radiation being absorbed near the surface, resulting in stable density stratification and causing it to be merely a heat transporter whose heat engine is ineffective (Munk and Wunsch, 1998). As a result, vertical (diapycnal) turbulent exchange is generally considerably weaker in the stratified ocean than in the atmosphere, with a net radiation flux that is positive. During the mainly nighttime cooling phase, the nearsurface ocean exhibits turbulent free convective overturning like that experienced by the daytime warming atmosphere but for a limited near-surface range $\mathrm{O}(10 \mathrm{~m})$ because the stable stratification requires large mechanical turbulence to break down the stored potential energy (e.g., Brainerd and Gregg, 1993, 1995; Price, Weller, and Pinkel, 1986). In shallow nearcoastal waters and near the ocean surface in general, a

DOI: 10.2112/JCOASTRES-D-19-00154.1 received 8 October 2019; accepted in revision 23 November 2019; corrected proofs received 31 January 2019; published pre-print online 4 March 2020.

${ }^{\circ}$ Coastal Education and Research Foundation, Inc. 2020 relatively strong solar daily rhythm is thus expected not only in temperature at a given depth but also in vertical temperature (density) stratification. The turbulent mixing associated with the turbulent convection because of cooling has values (Gregg et al., 1985) that are of the same order of magnitude as those associated with frictional flows in an energetic tidal channel (e.g., Korotenko et al., 2013) and with the breaking of large internal waves above steep topography in the deep ocean (e.g., van Haren et al., 2016).

In very shallow seas, another physical process may be so dominant that it counteracts the preceding oceanic diurnal cycle of turbulence convection and stable stratification. This process is the efficient (about 20\%, according to Hull, 1979) capturing of energy in so-called solar ponds. For example, nearbottom heating that may be stored in water where stable salinity-density stratification is found, as was observed in a Transylvanian lake (von Kalecsinsky, 1902). Because water is transparent to visible light but opaque to infrared radiation, a seafloor absorbs heat, which can only escape into the water column via conduction and, especially when not stably stratified, move higher into the water column via turbulent convection.

In this paper, shallow water temperature data are presented that are reminiscent of the solar pond process. They are observed during periods of little rain and generally clear waters, so solar insolation dominates temperature and stratification variations. In addition, temperature observations show internal waves supported by stratification that dominate over turbulence activity during part of the cooling phase. The 


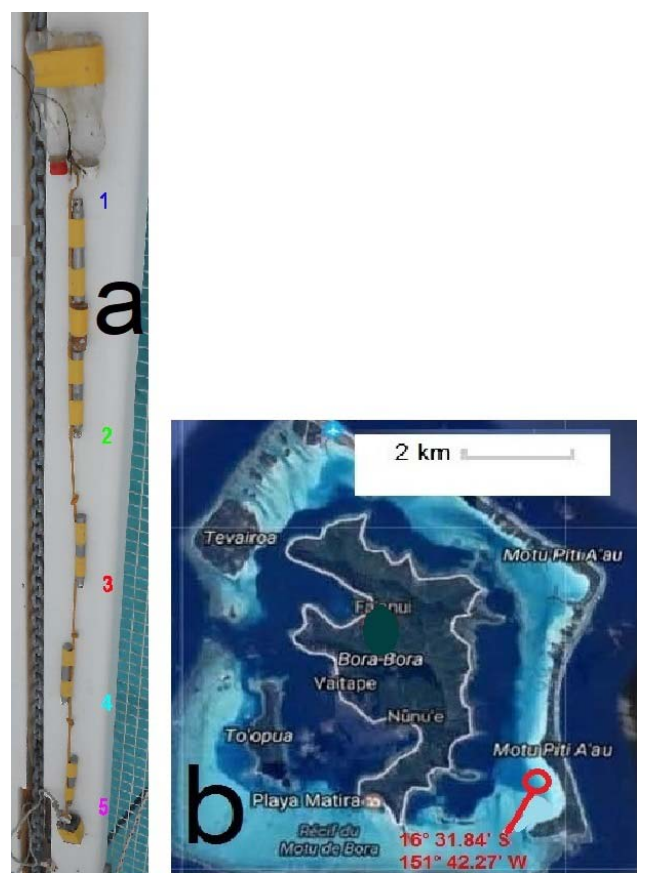

Figure 1. Mooring and site. (a) Mooring line laid out on the vessel's anchor chain guide. For reference, the high-resolution temperature sensor ( $\mathrm{T}$ sensor) housings are $0.18 \mathrm{~m}$ long. The two bottles constituting the top of the mooring provide $0.5 \mathrm{~kg}$ of net buoyancy. The uppermost T sensor tip is $0.05 \mathrm{~m}$ below the bottles' necks. The low-resolution pressure-temperature-salinity (PTS) sensor is between the first and the second uppermost T sensors. Originally, the distance between $\mathrm{T}$ sensors was $0.38 \mathrm{~m}$ (except where it was $0.45 \mathrm{~m}$ between the upper two sensors), but by tying knots, it was reduced to about $0.35 \mathrm{~m}$. The lowest sensor is about $0.05 \mathrm{~m}$ above the $1-\mathrm{kg}$ lead weight. (b) Mooring site (circle) in the lagoon near the Bora Bora atoll in the South Pacific. (Color for this figure is available in the online version of this paper.)

preceding physical process of daytime near-bottom heating may occur irrespective of, and add to, the biophysical process of microenvironment heating the first millimeter above specific shallow water corals, which has been demonstrated mainly in laboratory studies (Fabricius, 2006; Jimenez et al., 2008). A small-scale mooring holding five high-resolution temperature sensors ( $\mathrm{T}$ sensors) and a single low-resolution pressuretemperature-salinity (PTS) sensor (Figure 1a) was deployed in an approximately $2-m$ water depth near the anchor of a sailing vessel in the lagoon of Bora Bora, an island in the southern tropical Pacific (Figure 1b). The aim of the setup was to study details of the shallow lagoon's daily solar heating cycle and associated effect on temperature stratification at several depth levels. Observations were expected of alternating stably stratified and turbulent periods during the warming (approximately daytime) and cooling (approximately nighttime) phases, just like open-ocean near-surface observations (e.g., Brainerd and Gregg, 1993; Gregg et al., 1985; Price, Weller, and Pinkel, 1986; Soloviev and Lukas, 1997). Such an open-ocean daily cycle has been used to model the daily cycle in lagoons that have water depths varying between a few and several tens of meters (e.g., McCabe et al., 2010). This model contrasts with recent modeling of a $0.1-\mathrm{m}$-deep lake that is heated from below (de la Fuente, 2014). The present observations aimed to resolve which process is dominant under what conditions in the parts of a typical Pacific lagoon that are a few meters deep and where the tidal range is a few tenths of a meter, maximum.

\section{METHODS}

Eulerian temperature variations were observed using five stand-alone, high-resolution Royal Netherlands Institute for Sea Research (NIOZ) 4 sensors moored at a 2-m water depth with a relatively white sandy seafloor near the South Pacific tropical atoll of Bora Bora at $16^{\circ} 31.84^{\prime} \mathrm{S}, 151^{\circ} 42.27^{\prime} \mathrm{W}$ (Figure 1). According to Gischler (2011), the seafloor in the shallow (less than $5 \mathrm{~m}$ deep) back-reef sand apron on the eastern side of Bora Bora consists mainly of skeletal grains and 30 to $50 \%$ nonskeletal grains (cemented fecal pellets and aggregates). The mooring site is sheltered from surface waves and the E-SE trade wind. The topography is bumpy, with vertical variations of up to 0.3 to $0.6 \mathrm{~m}$ that are 0.5 to $1 \mathrm{~m}$ apart. The mooring line was put in a small trough in the vicinity of the anchor, with its $1-\mathrm{kg}$ weight buried. The total length of the mooring line was about $1.8 \mathrm{~m}$. Vertical sensor heights were measured at the 1$\mathrm{mm}$ glass tip. They were at $0.1,0.4,0.7,1.0$ and $1.5 \mathrm{~m}$ above the bottom (mab). The $\mathrm{T}$ sensors were sampled at a rate of $1 \mathrm{~Hz}$. Between the uppermost two sensors, a low-resolution Star-oddi PTS sensor was attached, which sampled at a rate of once every $600 \mathrm{~s}$. Thus, at only one level, around $1.3 \mathrm{mab}$, temperature information and salinity information were available that had an accuracy/resolution of $\pm 0.1 / 0.032^{\circ} \mathrm{C}$ and $\pm 1 / 0.02 \mathrm{~g} / \mathrm{kg}$, respectively. The PTS sensor was mainly used to roughly detect near-surface freshwater and surface-tide pressure variations. The line was held vertically by two plastic bottle floats on top, providing about $0.5 \mathrm{~kg}$ of net buoyancy. Hourly simulation meteorological information was obtained from Meteoblue (2019), while visual turbidity information was noted in a logbook.

The NIOZ4 $\mathrm{T}$ sensors are an improved version of NIOZ3 T sensors with basically the same characteristics, including precision better than $5 \times 10^{-4 \circ} \mathrm{C}$ and a noise level of less than $1 \times 10^{-4 \circ} \mathrm{C}$ (see van Haren et al., 2009, for details). In normal mooring configurations, the clocks of all $\mathrm{T}$ sensors are synchronized to a standard clock every 4 hours so that an entire profile is measured to within $0.02 \mathrm{~s}$. However, the somewhat bulky synchronizer was left out of the present small mooring line. Instead, before deployment, the entire mooring line was submersed rapidly in a different ambient temperature. The fast $(<0.25 \mathrm{~s})$ response of the $\mathrm{T}$ sensors allows for time shifts of this artificial temperature jump to be corrected.

Despite calibration to within a precision of about $1 \times 10^{-4 \circ} \mathrm{C}$ in the laboratory before and after deployments, the drift of the NIOZ4 sensors is about $1 \times 10^{-3 \circ} \mathrm{C} /$ month after aging. The normal postprocessing procedure corrects for this drift by forcing an average temperature profile to a smooth statically stable profile. This works well under the criteria that the number of sensors on a line is large, typically 100, and that temperature can be used as a tracer for density variations via a tight relationship. In the present case, neither of these two criteria is (always) met. During rainfall, the influx of fresh water can provide an overly large contribution of salinity on density variations compared with temperature contributions. 


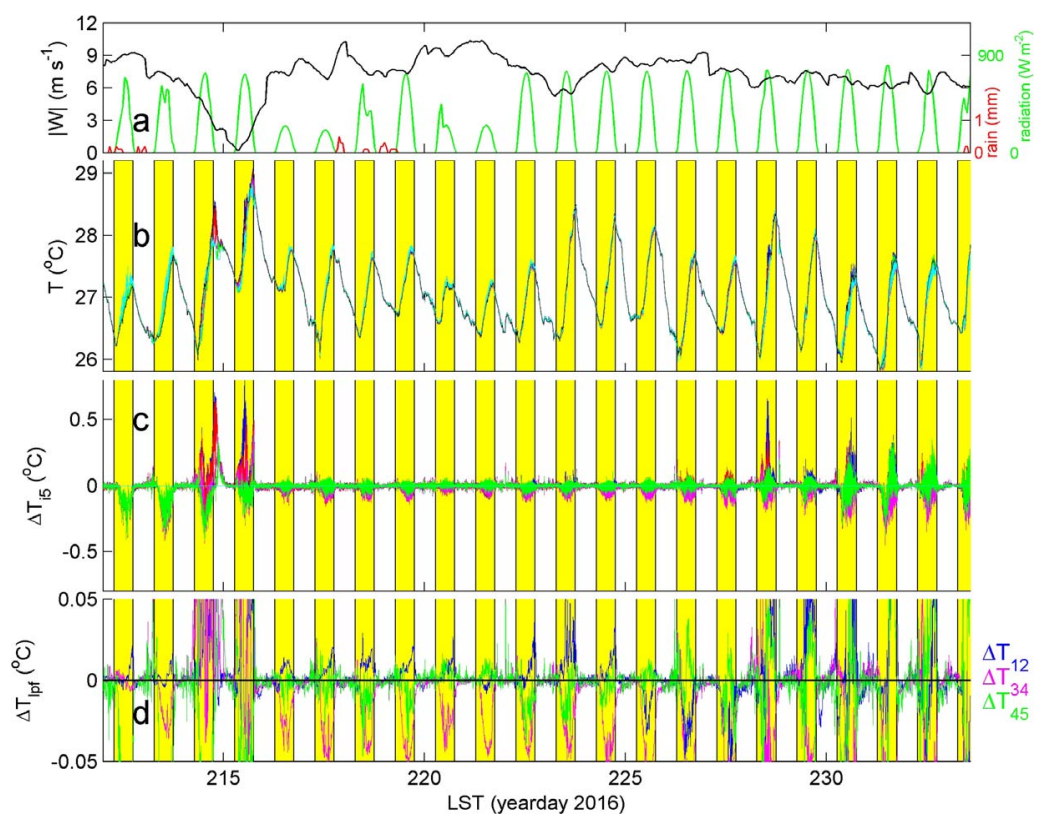

Figure 2. Entire time series of Bora Bora deployment in August 2016. Time is given in yeardays local solar time (LST), computed from the mooring site longitude. The yellow bars indicate periods of daytime, between sunrise and sunset. (a) Hourly meteorological information from the Meteoblue simulation, wind speed (in meters per second; black), short wave radiation (in watts per square meter; green, scale to right), rainfall (in millimeters; red, scale to right). (b) Water temperature for all moored sensors in the color range (blue, red, magenta, green, and cyan) from upper (first) to lower (fifth) sensors. (c) Temperature difference relative to the lowest (fifth) sensor (using the same colors as in panel b, so the zero line is cyan). (d) Low-pass filtered ( $\sim 40$ cycles per day [cpd] cutoff) temperature difference between three sets of neighboring sensors. (Color for this figure is available in the online version of this paper.)

This is remedied here by focusing on a period with virtually no rain, resulting in little observed variability in salinity near the surface. However, the number of $\mathrm{T}$ sensors cannot be altered, and a subjective fitting for an arbitrary, weakly unstable nighttime period between days 216.8 and 217.2 is performed to correct for drift. The small number of sensors also precludes estimates of turbulence using the method of overturning scales. Instead, qualitative turbulence information is obtained from scalar temperature variance spectra (Tennekes and Lumley, 1972), focusing on the buoyancy frequency range where a transition from stable stratification supporting internal wave propagation to unstable turbulence is expected. Internal waves are driven by any (shear) flow interacting with topography and have frequencies between Earth's rotational inertial frequency $f$ and mean buoyancy frequency $N$ (e.g., LeBlond and Mysak, 1978). Here, $N=\left(-g / \rho \cdot d \sigma_{\theta} / d z\right)^{1 / 2}$ using the local thermal expansion coefficient of $\Delta \sigma_{\theta} / \rho \Delta T \approx 3.1 \times 10^{-4 \circ} \mathrm{C}^{-1}$ for ambient PTS using Gibbs-Seawater software (IOC, SCOR, and IAPSO, 2010), with $g$ denoting the acceleration of gravity, $\rho$ as a reference density, and $\sigma_{\theta}$ as the potential density anomaly referenced to the surface. Variations in $\sigma_{\theta}$ are determined from temperature variations.

\section{RESULTS}

Like near-surface open-ocean waters, lagoon waters generally warm up during the day and cool during the night (Figure $2 \mathrm{~b}$ ). The diurnal rhythm was apparent in all temperature records of the present study, although its magnitude varies between days and between sensor depths. By computing the temperature variations relative to that of the lowest (fifth) $\mathrm{T}$ sensor (Figure 2c), positive and negative values were observed for $\Delta T_{i 5}=T_{i}-T_{5}, i=1, \ldots, 4$, which varied over the range $-0.4<$ $\Delta T_{i 5}<0.7^{\circ} \mathrm{C}$. A positive relative temperature gives rise to a stable density stratification, and a negative value suggests turbulent free convection (provided the salinity contributions to density variations are negligible). Sometimes, e.g., around days 215 and 230, and at some sensors, positive relative temperature was observed during the warming phase, as in general ocean heating. However, the relative temperature was often negative during the warming phase, with the temperature at the lowest (or second-lowest) $\mathrm{T}$ sensor being the highest. During days 212 and 213, the temperature at the lowest sensor was higher than that at all other sensors by up to $0.4^{\circ} \mathrm{C}$. In general, the relative temperature was $-0.2 \pm 0.1^{\circ} \mathrm{C}$ and the temperature at the second-lowest sensor was higher (as understood from the less negative relative temperature in Figure 2c) than at the sensors above it. During the cooling phase, the relative temperature initially became negative shortly after sunset, as is visible in records of near-surface and near-bottom stratification, i.e. the vertical temperature difference between neighboring sensors, in Figure 2d. (Note the change in the y-axis scale compared with Figure 2c). However, the water at the upper $\mathrm{T}$ sensors cooled more slowly than it did at the lower sensors, so the temperature difference became positive over time. The positive peak in temperature difference during the cooling phase was generally observed to occur at 


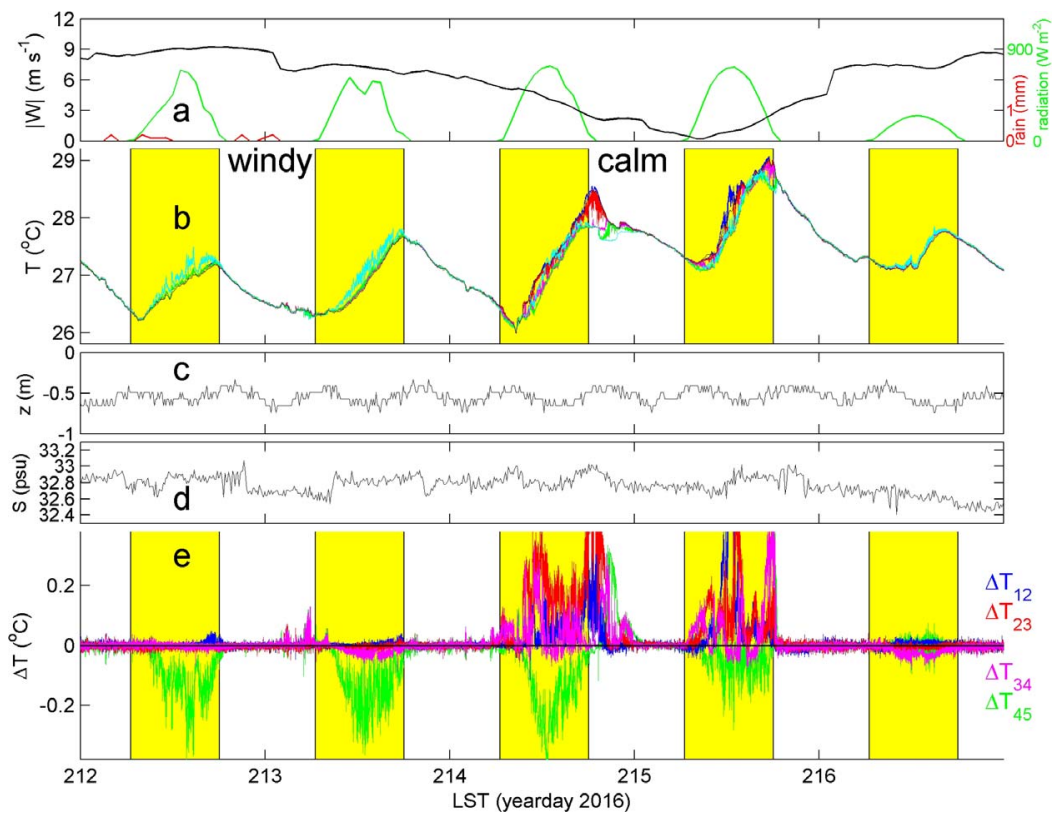

Figure 3. Five-day representative detail of Figure 2. (a) Hourly meteorological information. (b) Water temperature, with colors as in Figure 2b. (c) Depth (approximate pressure) variations as measured by the PTS sensor. (d) Salinity from the PTS sensor. The vertical scale is the same as that of panel b in terms of density contributions using the local thermal expansion coefficient. (e) Temperature relative to the lowest sensor, as in Figure $2 \mathrm{~d}$. (Color for this figure is available in the online version of this paper.)

sunrise, e.g., around days 220 and 230. After sunrise, cooling continued for approximately another 1 to 3 hours (Figure 2b), while the temperature difference dropped to nearly zero (Figure 2d).

In Figure 3, the first 5 days of the record are presented in more detail and comprise various dynamics. As for most of August (Figure 2a), these 5 days were without substantial precipitation and without detected freshwater influx near the surface. Days 212 and 213 showed a significant easterly trade wind with speeds of about $9 \mathrm{~m} \mathrm{~s}^{-1}$ (Figure 3a) and agitation with clear waters over the mooring (logbook information). Days 214 and 215 were relatively calm, with wind speeds of less than $6 \mathrm{~m} \mathrm{~s}^{-1}$ and some turbid waters over the mooring (probably because of materials from the main island to the NW). The vertical temperature variation on day 216 was representative for the next 10 days of the record. The salinity variation (Figure $3 \mathrm{~d}$ ) did not show negative spikes (strong decreases in value), evidencing no freshwater (rainfall) influx. Salinity followed a statistically insignificantly diurnal periodicity that was not related to the predominant semidiurnal tidal pressure variation. The barotropic surface tidal variations had an amplitude in pressure of $0.1 \mathrm{dbar}$, or about $\pm 0.1 \mathrm{~m}$ in surface height variation (Figure 3c). This was consistent with the generally small tidal height variation in the Bora Bra lagoon (see also Tides Chart, 2019). The quasidaily salinity variation most likely reflects indirect effects of fouling, with imprecise temperature and conductivity data mismatches resulting in erroneous salinity data. The PTS sensor was not cleaned during its operation. The basic mean level of salinity steadily declined with time (hence the present mean value was $32.8 \mathrm{psu}$, whereas the approximate local values were around $35 \mathrm{psu}$ ). Therefore, little value can be extracted from these data. The temperature-salinity relationship also could not be determined properly because of the large noise of the PTS sensor.

The observed temperature variations with near-bottom warming during the day (Figure $3 \mathrm{~b}$ ) are plotted as contours in the appendix for a different viewpoint. The maximum observed stratification $\Delta T>0$ (Figure 3e) yielded a local buoyancy frequency of $N_{1.5 \mathrm{~m}} \approx 4 \times 10^{-2} \mathrm{~s}^{-1}$. This vertical density stratification supports freely propagating internal waves with periods as short as $150 \mathrm{~s}$. Possibly, and as will be inferred from spectral observations later, higher-frequency $(\sigma)$ internal wave motions up to $\sigma=10^{-1} \mathrm{~s}^{-1}$ (supported by maximum small-scale $N_{\text {max }} \approx 1400 \mathrm{cpd}$, short for cycles per day) existed briefly because of unresolved thin $(<0.35 \mathrm{~m})$ layer stratification. The typically observed low-value stratification during the cooling phase yielded $N_{1} \approx 3 \times 10^{-3} \mathrm{~s}^{-1}\left(N_{1}\right.$ $\approx 45 \mathrm{cpd}$ ).

The largest stratification in Figure 3e was found during the warming phase and near the surface, but only on calm days (Figure 3a), like on days 214 and 215 with turbid waters (logbook information). On days 212 and 213 of trade winds (Figure 3a), waters were clear and the warming phase showed little stratification except between the two uppermost $\mathrm{T}$ sensors near the end of warming (Figure 2d). Instead, near-bottom temperature increased the most (Figures $3 b$ and A1) and temperature instabilities $\Delta T<0$ are shown in Figure 3e between the lowest two sensors: sensors 4 and 5 (day 212) and sensors 3 and 4 (day 213). 


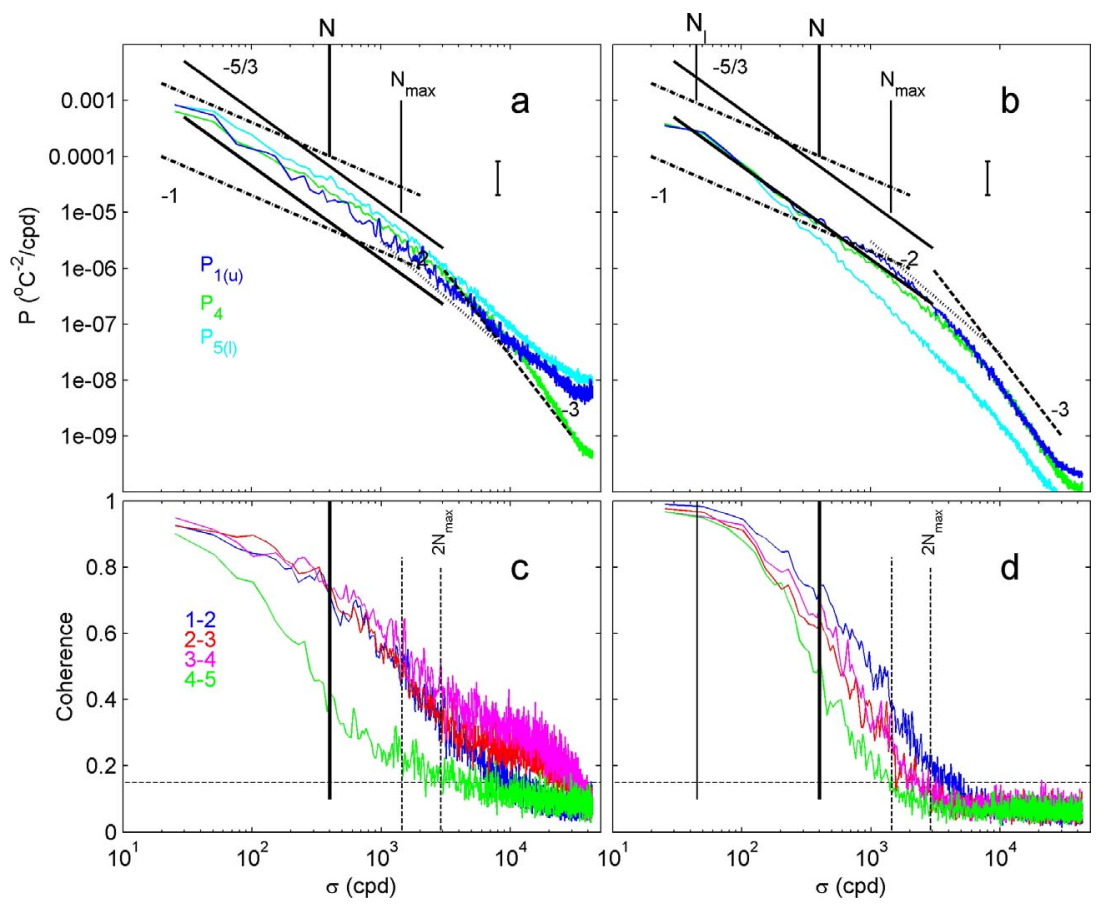

Figure 4. Smooth spectra for data from day 216 to day 228. (a) Temperature variance spectra for three levels of warming phase data during the day between $x x .37$ and $x x .77$, with $x x$ denoting an arbitrary yearday. Some spectral slopes (log-log scale) are given by straight black lines: These lines are the same in all following variance spectra and may be used for reference. (b) As in panel a, but for cooling phase data between day.87 and (day+1).27. (c) Coherence spectra for pairs of neighboring sensors for warming phase data. The horizontal dashed line indicates the approximate $95 \%$ significance coherence level. (d) As in panel c, but for the cooling phase. (Color for this figure is available in the online version of this paper.)

The largest negative temperature differences were observed around midday, when the sun was highest. The larger temperature increase at the lowest sensor in particular, and to a lesser extent at the second lowest sensor, was accompanied by an increase in short-term temperature variability. This started about 2.5 hours after sunrise and stopped within \pm 0.5 hour from sunset. It showed the sun heating the bottom and thus the water from below. Unless compensated by salinity stratification, this would create a static instability throughout the warming phase. The rapid temperature variability observed at the lowest sensor or sensors points at such, but more qualitative information is gained from spectral analysis. Spectra were also used to investigate whether shear-induced turbulence prevents convection from developing toward the surface, as the $\mathrm{T}$ sensor time series observations suggest.

During the warming phase, the apparent temperature instability, especially near the bottom, was reflected in temperature variance spectra (Figure 4a). The spectra are smooth ensembles of 13 approximate daytime periods of 10 hours of data. The spectrum of the uppermost sensor showed the lowest variance during the warming phase. This spectrum scaled with a frequency rate of $\sigma^{-5 / 3}$ (which yielded a slope of -5 / 3 on a log-log scale) between 20 and $2000 \mathrm{cpd}$ before rolling off. The $-5 / 3$ slope reflects the inertial subrange of turbulence, which extended over a range of two orders of magnitude. The inertial subrange represents a passive scalar shear-induced turbulence (Tennekes and Lumley, 1972). In contrast, the more energetic spectra from data of the lower sensors (here presented by the fifth sensor) showed a slope between $-5 / 3$ and -1 in the range between 50 and $2000 \mathrm{cpd}$. This intermediate slope of about -1.3 reflects a dominant active scalar convective turbulence (Cimatoribus and van Haren, 2015). The slope of -1 was indicative for open-ocean internal waves (van Haren and Gostiaux, 2009).

During the cooling phase, the 13 approximate nighttime smooth spectra of 10 hours of data (Figure 4b) showed different slopes. In comparison with the warming phase spectra, the temperature variance was smaller at all frequencies and at all sensors. In the frequency range under investigation, the smoothest temporal variations and smallest spectral variance were observed at the lowest sensor. The spectrum for this fifth sensor showed a steep slope between -2 (for $\sigma<5000 \mathrm{cpd}$; this slope is indicative of fine structure contamination, Phillips, 1971) and -3 before ending in white noise at $\sigma>2 \times 10^{4} \mathrm{cpd}$. (In all spectra, the entire vertical range of variance was ten orders of magnitude). The uppermost sensor (representing all other sensors) showed a slightly more convective slope between -1 (around $N$ ) and $-5 / 3$ (between 20 and $200 \mathrm{cpd}$ ). At frequencies $\sigma$ $<30 \mathrm{cpd}$ in the presented range, the slope equaled -1 , indicative of dominant internal waves (van Haren and Gostiaux, 2009), at all sensors.

Coherence spectra comparing data from neighboring $\mathrm{T}$ sensors (Figure 4c,d) confirmed the power spectra observa- 


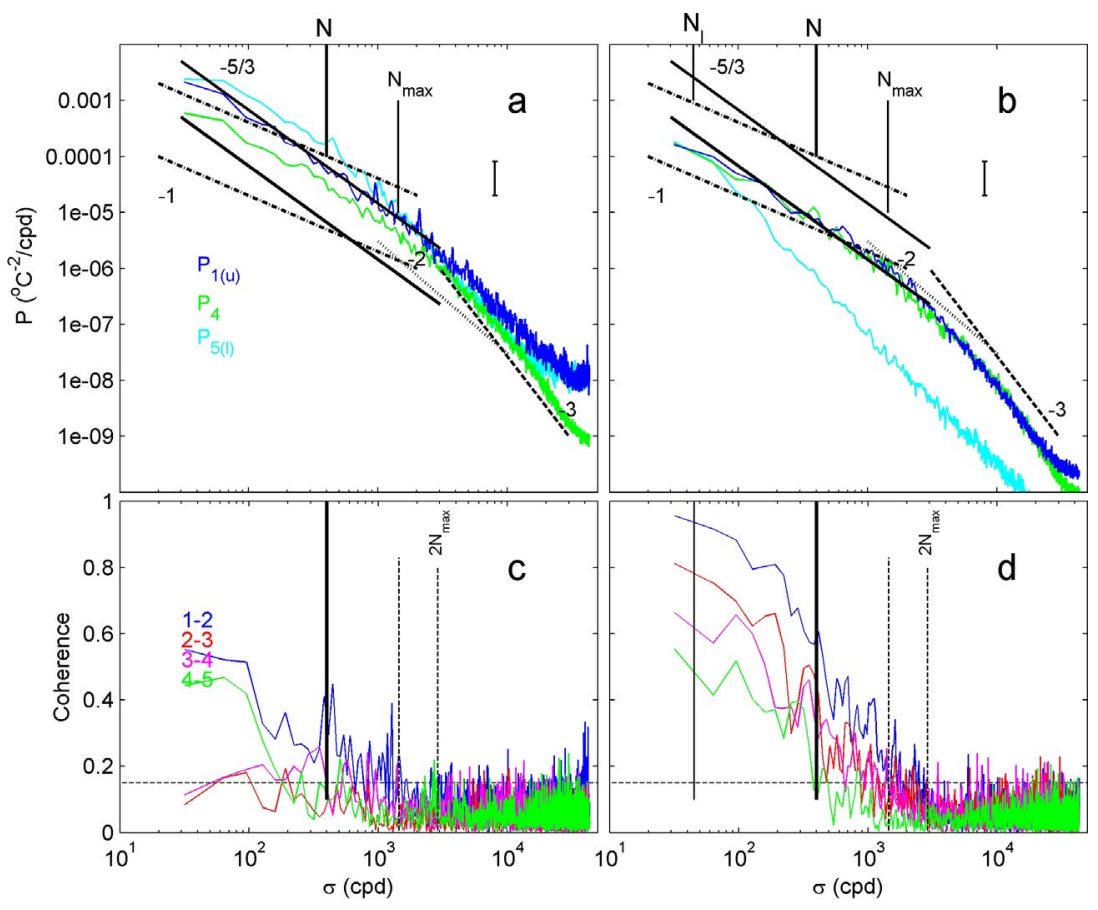

Figure 5. As in Figure 4, but for calm days 214 and 215 with turbid near-surface waters. (Color for this figure is available in the online version of this paper.)

tions. Coherence was generally less during the warming phase (Figure 4c) than during the cooling phase (Figure 4d), but for $\sigma$ $<100 \mathrm{cpd}$ only. This suggests (highly coherent) internal wave motions were relatively more important during the cooling phase at all sensors. For $\sigma>100 \mathrm{cpd}$, the coherence during the warming phase was larger than that during the cooling phase, except near the seafloor for $100<\sigma<1000 \mathrm{cpd}$. The large extent of significantly coherent signals for $\sigma>2 N_{\max }$ points at extended turbulence activity in nonhomogeneous waters (van Haren et al., 2016).

Other moderately smoothed spectra of 10-hour periods from days 214 (weak wind and turbid waters) in Figure 5 and 212 (strong wind and clear waters) in Figure 6 showed similar features that were perhaps somewhat more pronounced. During the warming phase, the data from upper (and middle) $\mathrm{T}$ sensors showed a $-5 / 3$ slope over most of the investigated range for $\sigma<2000 \mathrm{cpd}$, while the more energetic lowest sensor data showed a slightly less steep slope between $-5 / 3$ and -1 for $\sigma<400 \mathrm{cpd}$ (Figure 6a). During the cooling phase, the small variance at the lowest sensor sloped steeply at rates of less than -2 down to -3 . Spectra from data of the other sensors also showed less variance than during the warming phase but had an average slope of $-5 / 3$ between 20 and $2000 \mathrm{cpd}$, with distinct patches of slopes of -1 , especially around $N$, evidencing highfrequency internal wave activity.

Although the coherence spectra from the cooling phase were approximately similar for data from all sensors during both periods, dropping to insignificance levels between $100<$ $\sigma<1000 \mathrm{cpd}$, coherence was different between the two periods for the warming phase. During the warming phase, correspondence was insignificant (noncoherent) between all depth levels at all frequencies for days 214 and 215 (Figure 5c). In contrast, it was coherent between all levels, except near the seafloor, at nearly all $\sigma<10^{4} \mathrm{cpd}$ for days 212 and 213 (Figure 6c).

\section{DISCUSSION}

It seems that shallow lagoons can resemble the atmosphere by being heated from below. Part of the solar radiation penetrates to the seafloor when waters are clear. If so, either its partial reflection or its conduction heat the water from below. As a result, near-bottom temperature and temperature variance (of fluctuations) are high during the warming phase. The temperature fluctuations partially suggest strong turbulent motions. The observed abrupt change from strongest to weakest turbulence near the seafloor relative to higher up at sunset (and vice versa 2 hours after sunrise) further demonstrates the directly solar-driven heating from below. In the absence of (knowledge on) salinity contributions to density, one would consider turbulent motions because of heating from below to be primarily convectively driven.

However, the qualitative analysis of scalar temperature variance spectra focusing on the frequency range around $N$ shows that the created turbulence has a dominating character of shearing motions, especially away from the lagoon floor. This suggests that shear-induced turbulence prevents convection from developing further upward toward the surface, that vertical motions related to convection generate secondary shear ( $\mathrm{Li}$ and $\mathrm{Li}, 2006$ ), or perhaps unlikely, that horizontal motions are generated following differential heating over 


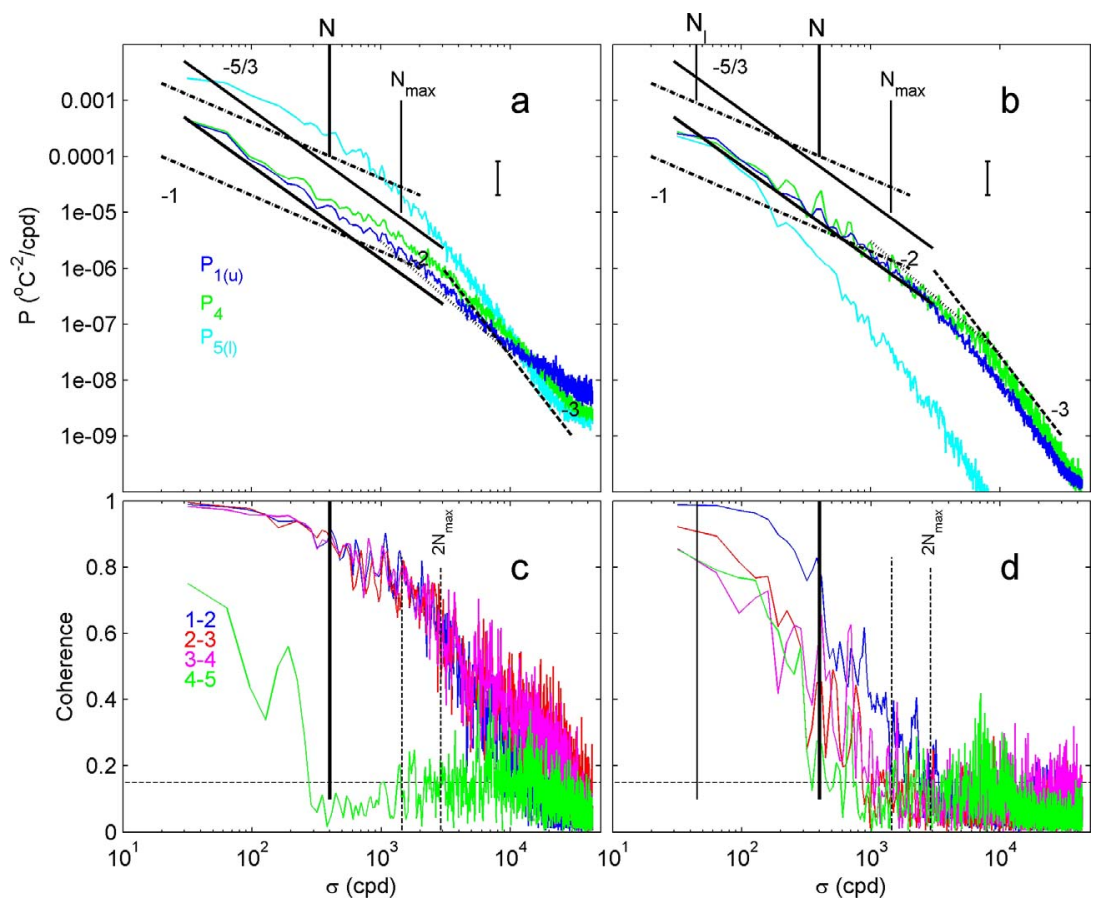

Figure 6. As in Figure 5, but for windy days 212 and 213 with clear waters. (Color for this figure is available in the online version of this paper.)

slightly different water depths because of the bumpy topography, with possibly varying reflective and absorption properties.

Although near-bottom salinity observations are lacking, little evidence is found for an effective solar pond in the Bora Bora lagoon that retains large heat content close to the lagoon floor via turbulence-dampening salt stratification. During the cooling phase, at sunset, all near-bottom surplus heat content is rapidly lost instead of being maintained throughout the night. This indirectly shows weak salinity stratification. The observed minimum vertical temperature difference is $\Delta T \geq$ $-0.4^{\circ} \mathrm{C}$, and spectra do not show clear internal wave slopes, evidencing salinity or density stratification during the warming phase. The weak cooling phase stratification, generated by $\Delta T \approx+0.01^{\circ} \mathrm{C}$ providing $N_{1}$, is roughly supported by internal wave spectral slopes. The transition from near-complete coherence at $\sigma<N_{1}$ to insignificant near-zero coherence more than 1 to 2 orders of frequency range has been previously found to describe the transition from two-dimensional stratified turbulence to full three-dimensional isotropic turbulence associated with internal wave breaking above a deep-ocean seamount (van Haren et al., 2016).

As indicated in the cartoon of Figure 7, shallow, relatively clear waters such as in lagoons can thus be quite different in their daily heating-cooling pattern compared with the nearsurface open ocean. During the warming phase, turbulent shear convective overturning is generated near the seafloor because of the heating from below, in addition to stable stratification from the surface down (which is also mixed downward under windy conditions, like in the open ocean; see, e.g., Price, Weller, and Pinkel, 1986). During the cooling phase, the site not only is governed by turbulent free convection, as observed in the ocean, but also is seen to develop a weak stratification that supports linear and nonlinear internal waves. This is probably because of the sudden absence of
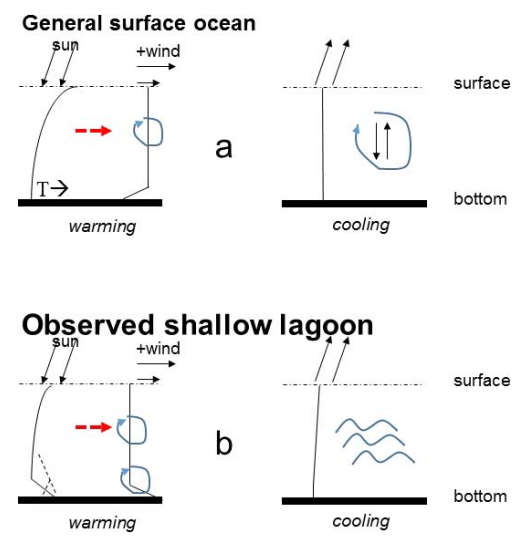

Figure 7. Sketches of vertical temperature profiles following oceanatmosphere interactions for warming phase (left; dominant incoming solar radiation with possible wind shear stress) and cooling phase (right; dominant outgoing radiation generating convective turbulence). (a) Consensus for open-ocean (near-surface) conditions becoming stratified during warming phase and convectively well-mixed during cooling phase (e.g., Brainerd and Gregg, 1993). (b) Present observations leading to the hypothesis for shallow lagoons becoming heated from below including turbulent motions during warming phase and being weakly stratified including internal waves in the water column during cooling phase. (Color for this figure is available in the online version of this paper.) 
seafloor heating when sun radiation and conduction stop. The associated strong reduction of near-bottom turbulence transfers upward, like in the nighttime atmosphere (Nieuwstadt and Brost, 1986).

The observed physical processes of near-bottom heating during the warming phase and stratification during the cooling phase should be taken into account for lagoon modeling, some of which thus far have adopted open-ocean warming-cooling processes only (e.g., McCabe et al., 2010). Very shallow $(<0.1$ $\mathrm{m})$ water-depth lake modeling proved the possibility of nearbottom heating (de la Fuente, 2014). Future lagoon modeling should also account for the additional biophysical process of microenvironment heating of particular (dark) shallow water corals and reef formation (Fabricius, 2006; Jimenez et al., 2008) that adds to the presently observed physical process of heating from below in a shallow lagoon.

The present observations are from above a depression in a more or less white lagoon floor. The same process with similar temperature differences was seen in observations from above the darker bottom just outside Apooiti marina (Tahiti) using the same instrumentation (not shown) and episodically in shallow water of a tidal flat sea on a calm summer day (van Haren, 2019). The physical process of solar pond heating in a stable salt stratification (von Kalecsinsky, 1902) may be observable in open-sea-connected and open-sea-flushed lagoons and even in the open ocean after rainfall, as may have been the case (but not discussed) in observations by Soloviev and Lukas (1997). However, near-bottom heating has not been observed in turbid waters like near a North Sea beach on a quiescent summer day with no wind-wave action (van Haren et $a l ., 2012$ ), which must result from the lack of solar radiation penetration at the bottom in waters that have a few tenths of a meter of visibility.

\section{CONCLUSIONS}

High-resolution moored T sensors observed physical processes of near-bottom heating during the (daytime) warming phase and stratification during the (nighttime) cooling phase. This contrasts with open-ocean warming-cooling processes, and shallow lagoons resemble the atmosphere more than the open ocean by being heated from below. Highly variable temperature fluctuations partially suggest strong turbulent motions during the warming phase. The observed abrupt change from strongest to weakest turbulence near the seafloor relative to shallower depths at sunset (and vice versa 2 hours after sunrise) further demonstrates directly solar-driven heating from below. In the absence of (knowledge on) salinity contributions to density, one would consider turbulent motions because of heating from below to be primarily convectively driven.

\section{ACKNOWLEDGMENTS}

I thank C. Millot for his critical comments and the overboard operations from the S/V Orua, M. Laan for his T sensor assistance, and F. Bosveld for his explanation on the contrast between water and air convection. NIOZ $\mathrm{T}$ sensors have been partially funded by the Netherlands Organization for the Advancement of Science.

\section{LITERATURE CITED}

Brainerd, K.E. and Gregg, M.C., 1993. Diurnal restratification and turbulence in the oceanic surface mixed layer. 1. Observations. Journal of Geophysical Research, 98(C12), 22,645-22,656.

Brainerd, K.E. and Gregg, M.C., 1995. Surface mixed and mixing layer depths. Deep-Sea Research, 42(9), 1521-1543.

Cimatoribus, A.A. and van Haren, H., 2015. Temperature statistics above a deep-ocean sloping boundary. Journal of Fluid Mechanics, $775,415-435$.

de la Fuente, A., 2014. Heat and dissolved oxygen exchanges between the sediment and water column in a shallow salty lagoon. Journal of Geophysical Research, 119, 596-613.

Fabricius, K.E., 2006. Effects of irradiance, flow, and colony pigmentation on the temperature microenvironment around corals: Implications for coral bleaching? Limnology and Oceanography, 51(1), 30-37.

Gischler, E., 2011. Sedimentary facies of Bora Bora, Darwin's type barrier reef (Society Islands, South Pacific): The unexpected occurrence of non-skeletal grains. Journal of Sedimentary Research, 81(1), 1-17.

Gregg, M.C.; Peters, H.; Wesson, J.C.; Oakey, N.S., and Shay, T.J., 1985. Intensive measurements of turbulence and shear in the equatorial undercurrent. Nature, 318, 140-144.

Hull, J.R., 1979. Physics of the Solar Pond. Ames: Iowa State University, Ph.D. dissertation, 130p.

IOC (Intergovernmental Oceanographic Commission), SCOR (Scientific Committee on Oceanic Research), and IAPSO (International Association for the Physical Sciences of the Oceans), 2010. The International Thermodynamic Equation of Seawater-2010: Calculation and Use of Thermodynamic Properties. Paris: UNESCO, Intergovernmental Oceanographic Commission, Manuals and Guides No. 56, 196p.

Jimenez, I.M.; Kühl, M.; Larkum, A.W.D., and Ralph, P.J., 2008. Heat budget and thermal microenvironment of shallow-water corals: Do massive corals get warmer than branching corals? Limnology and Oceanography, 53(4), 1548-1561.

Korotenko, K.; Sentchev, A.; Schmitt, F.G., and Jouanneau, N., 2013. Variability of turbulent quantities in the tidal bottom boundary layer: Case study in the eastern English Channel. Continental Shelf Research, 58, 21-31.

LeBlond, P.H. and Mysak, L.A., 1978. Waves in the Ocean. New York: Elsevier, 602p.

Li, S. and Li, H., 2006. Parallel AMR Code for Compressible MHD and HD Equations. T-7, MS B284, Theoretical division. Los Alamos, New Mexico: Los Alamos National Laboratory. http://math.lanl. gov/Research/Highlights/amrmhd.shtml

McCabe, R.M.; Estrade, P.; Middleton, J.H.; Melville, W.K.; Roughan, M., and L. Lenain, 2010. Temperature variability in a shallow, tidally isolated coral reef lagoon. Journal of Geophysical Research, 115, C12011. doi:10.1029/2009JC006023

Meteoblue, 2019. Weather Archive Bora Bora. https://www.meteoblue. com/en/weather/forecast/archive/bora-bora_french-polynesia_ 4034582

Munk, W. and Wunsch, C., 1998. Abyssal recipes II: Energetics of tidal and wind mixing. Deep-Sea Research I, 45, 1977-2010.

Nieuwstadt, F.T.M. and Brost, R.A., 1986. The decay of convective turbulence. Journal of the Atmospheric Sciences, 43(6), 532-546.

Peixoto, J.P. and Oort, A.H., 1992. Physics of Climate. New York: AIPPress, 520p.

Phillips, O.M., 1971. On spectra measured in an undulating layered medium. Journal of Physical Oceanography, 1(1), 1-6.

Price, J.F.; Weller, R.A., and Pinkel, R., 1986. Diurnal cycling: Observations and models of the upper ocean response to diurnal heating, cooling, and wind mixing. Journal of Geophysical Research, 91(C7), 8411-8427.

Sandström, J.W., 1908. Dynamische Versuche mit Meerwasser. Annalen der Hydrographie und Maritimen Meteorologie, 36, 6-23.

Soloviev, A. and Lukas, R., 1997. Observation of large diurnal warming events in the near-surface layer of the western equatorial Pacific warm pool. Deep-Sea Research I, 44(6), 1055-1076.

Tennekes, H. and Lumley, J.L., 1972. A First Course in Turbulence. Cambridge, Massachusetts: MIT Press, 293p. 
Tides Chart, 2019. Bora-Bora Tide Times and Tide Charts. https://www. tideschart.com/French-Polynesia/Leeward-Islands/Bora-Bora/

van Haren, H., 2019. Turbulent convection and high-frequency internal wave details in 1-m shallow waters. Limnology and Oceanography, 64, 1323-1332.

van Haren, H.; Cimatoribus, A.A.; Cyr, F., and Gostiaux, L., 2016. Insights from a 3-D temperature sensors mooring on stratified turbulence. Geophysical Research Letters, 43, 4483-4489. doi:10. 1002/2016GL068032

van Haren, H. and Gostiaux, L., 2009. High-resolution open-ocean temperature spectra. Journal of Geophysical Research, 114, C05005. doi:10.1029/2008JC004967

van Haren, H.; Gostiaux, L.; Laan, M.; van Haren, M.; van Haren, E.; and Gerringa, L.J.A., 2012. Internal wave turbulence near a Texel beach. PLoS ONE, 7(3), e32535. doi:10.1371/journal.pone.0032535

van Haren, H.; Laan, M.; Buijsman, D.-J.; Gostiaux, L.; Smit, M.G., and Keijzer, E., 2009. NIOZ3: Independent temperature sensors sampling yearlong data at a rate of $1 \mathrm{~Hz}$. IEEE Journal of Oceanic Engineering, 34(3), 315-322.

von Kalecsinsky, A., 1902. Ueber die ungarischen warmen und heissen Kochsalzseen als natürliche Wärmeaccumulatoren, sowie über die Herstellung von warmen Salzseen und Wärmeaccumulatoren. Annalen der Physik IV, 2, 408-416.

\section{APPENDIX}

A different view of diurnal variation of lagoon warming and cooling after transferring Figure $3 \mathrm{~b}$ to contours of constant temperature (Figure A1). In Figure A1, daytime warming is observed to start near the lagoon floor, which is at the horizontal axis, with contours bending to the right and upward.

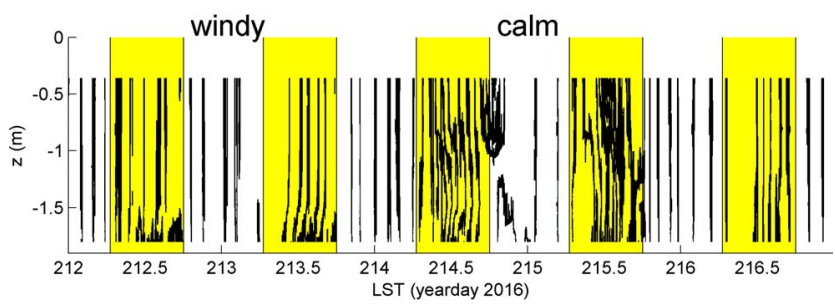

Figure A1. Temperature contours every $0.25^{\circ} \mathrm{C}$ for Figure $3 \mathrm{~b}$. (Color for this figure is available in the online version of this paper.) 